\title{
MITOLOGIA, ALEGORIA E ATEÍSMO PRÁTICO ${ }^{1}$
}

\section{Mythology, allegory and practical atheism}

\author{
Antonio José Romera Valverde
}

Professor do Departamento de Filosofia da PUC-SP e do Departamento de Fundamentos Sociais e Jurídicos da Administração da EAESP-FGV-SP.

e-mail: valverde@pucsp.br

"A Europa, depois de ter vivido à sombra da Antigüidade, passou a viver à luz dela outra vez."

(HUIZINGA, 1996)

"La mitología no es una vanidad de los diccionarios; es un eterno hábito de las almas." (BORGES, 1984)

\section{Resumo}

Sob o pano de fundo do fenômeno histórico-social da secularização, em curso desde o século XII, o artigo-ensaio analisa e discute os nexos entre mitologia, alegoria, história e ateísmo prático, durante o Renascimento. E ilustra com a obra De Sapientia Veterum, de Francis Bacon.

Palavras-chave: Filosofia; Renascimento; Mitologia; Bacon.

1 O artigo é parte da pesquisa "O Homem do Renascimento: o homem como medida", patrocinada pelo NPP da EAESP-FGV-SP.

Rev. Filos., v. 19, n. 24, p. 61-75, jan./jun. 2007 


\section{Abstract}

In the context of the historical-social phenomenon of the secularization, in progress since the XI century, the articleessay analyzes and argues the connections among mythology, allegory, history and practical atheism, during the Renaissance. And illustrates with the work Of Sapientia Veterum, of Francis Bacon.

Keywords: Philosophy; Renascency; Mitology; Bacon.

\section{Introdução}

O Renascimento foi o primeiro período histórico que pôde escolher um passado para si próprio. Os povos feudais haviam recebido o passado pronto, sob a forma de mito judaico-cristão. Nem os gregos desvincularam-se do mito, ao contrário, incorporaram-no - num movimento duplo de passagem e ruptura - ao nascente pensamento filosófico, como Vernant demonstrou, no detalhe (VERNANT, 1973). Escolher um passado significa que um povo ou, de modo anacrônico, as "classes sociais" de uma dada época selecionam da história e dos mitos, interpretados historicamente, aqueles com os quais encontram afinidades. O passado, privilegiado pelo Renascimento, reconhecido pela similitude de ideais, foi buscado na Antiguidade, mais visivelmente no passado da história romana. O culto da língua latina, o domínio da oratória como gênero e a citação de autores latinos são sinais desta escolha seletiva. Outro sinal consistia no viver e no descrever acontecimentos e conflitos reais contemporâneos, mas presentificados a partir da história romana. Dentre outros autores, Maquiavel nos Discorsi sopra la Prima Deca di Tito Livio confirma o fato ao revivificá-los e reinterpretá-los para além deles.

O Renascimento não constituiu um mero retorno à Antiguidade, mas antes a identificação de ideais clássicos favoráveis ao desenvolvimento burguês. E o pensamento e a sensibilidade dos humanistas do Renascimento enraizaram-se tanto na tradição judaico-cristã quanto sob uma nova visão dos ideários contidos na cosmovisão greco-romana, porém em nova chave de análise e assimilação crítica. O conteúdo temático desenvolvido pelos humanistas dá conta desta novidade. A propósito, Huisinga (1996) escreveu: 
[...] a essência da grande renovação reside menos no paganismo do que na pura latinidade. A expressão clássica e mesmo os sentimentos trazidos da Antigüidade pagã podem ter sido um estímulo poderoso ou um apoio indispensável no processo de renovação cultural, mas não foram a sua determinante. A alma da Cristandade Ocidental tentava libertar-se das formas e dos modos de pensamento que a agrilhoavam. A Idade Média sempre vivera à sombra da Antigüidade, sempre se servira dos seus tesouros, interpretando-os segundo os verdadeiros princípios medievais: teologia escolástica e cavalaria, ascetismo e cortesia. Ora, devido a um amadurecimento profundo, depois de se ter por tanto tempo familiarizado com as formas da Antigüidade, começou a apreender-lhe o espírito. A incomparável simplicidade e pureza da cultura antiga, a sua nitidez de concepção e de expressão, o seu pensamento natural e fácil e o vivo interesse pelo homem e pela vida - tudo isso começou a clarear nos espíritos. A Europa, depois de ter vivido à sombra da Antiguidade, passou a viver à luz dela outra vez.

O progresso da atitude renascentista foi o oposto da visão comum difundida, de que o homem do Renascimento encontrou na cultura antiga algo diferente $\mathrm{e}$ - por meio de um caldo cultural - projetou identificarse. Em verdade, a descoberta da Antiguidade gerou um sentido de identidade. Os humanistas do Renascimento pensaram encontrar cada vez mais semelhanças entre sua época e o passado distante. O reconhecimento do caráter distintivo foi produto de um grau relativamente elevado de desenvolvimento e esteve ligado às primeiras descobertas técnicas e científicas modernas. Contudo, o sentido deste caráter distintivo social só se tornou consciente quando as relações sociais burguesas tornaram-se reconhecíveis. Em parte, tal se deu desde o momento em que a burguesia principiou por auto-reconhecer-se como classe social, quiçá - de modo emblemático - na pessoa de Lorenzo de Medici, banqueiro, industrial, comerciante, mecenas das artes, poeta, ao perspectivar em Florença o ensaio - avant la lettre - de uma globalização.

Os humanistas do Renascimento trataram os pensadores e o pensamento da Antiguidade com autonomia e o fizeram da perspectiva de herdeiros da cultura cristã, que conheciam sobremaneira. Em consequiência, foi inegável que o entendimento dos problemas clássicos da Filosofia e as questões emergentes, com que se confrontaram os filósofos renascentistas, tivessem soluções aos moldes da tradição, por decorrência do desenvolvimento da cultura cristã, desde a invenção do "ideal de cultura cristã" projetado por Agostinho de Hipona, ao crepúsculo da Antiguidade. A atitude dos humanistas 
para com a Antiguidade greco-romana e o judaico-cristianismo fundava-se na procura de um lastro comum entre ambos. A configuração dos conflitos encontrava-se sugerida pelos embates teóricos entre dogma e espírito crítico, entre fé e conhecimento racional - temas caros a Lutero e à Companhia de Jesus. A relação entre Filosofia medieval e a Filosofia Antiga - do ponto de vista do filósofo renascentista - foi considerada quase sempre dogmática. A atitude basilar da Filosofia medieval fundava-se na fé como dom gratuito de Deus, fé que o conhecimento racional deveria justificar. ${ }^{2}$ A atitude da Filosofia renascentista para com a Antiguidade e a tradição judaico-cristã, de outro lado, operava pela crítica e em busca do conhecimento racional profano. Neste passo, a cultura renascentista foi a primeira a conectar conscientemente a Antiguidade grecoromana e a tradição judaico-cristã para além dos aspectos ideológicos da tradição medieval. E o "manifesto" humanista de Pico della Mirandola, Oratio de Hominis Dignitate, é em grande parte expressão da consciência de tal assimilação crítica.

Embora o processo de secularização como fenômeno sócio-histórico tenha principiado a meados do século XII, uma consequiência de tal fusão e choque culturais foi a secularização dos problemas cotidianos e éticos que durante o final da Idade Média emergiam sob disfarce religioso. Desde a aurora do Renascimento, a crença na missão da Igreja, o reconhecimento da hierarquia eclesiástica e a devoção religiosa tinham-se separado numa multiplicação de planos. Uma das causas do surgimento de heresias, dentre outras tantas, provém das aspirações de um "Estado" Papal, ${ }^{3}$ com pretensões econômicas e de poder, que se evidenciaram cada vez mais, e, de modo extremado, com Inocêncio VIII, Alexandre VI, Júlio II e, até mesmo, com Leão X, com estratégias diferençadas entre si. E um sintoma foi o fato dos movimentos heréticos serem hostis, coletivos e organizados. Estes fatores, além das novas condições de vida burguesa, produziram juntos duas novas atitudes frente à religião: uma atitude convencional - as práticas externas a divergirem do conteúdo interno, transformavam-se numa

2 Agostinho de Hipona e Tomás de Aquino, de maneiras diversas, debruçaram-se sobre o problema em tela. E em Paulo de Tarso, duas passagens distintas indicam as origens das linhagens espirituais do cristianismo, resolvidas por Agostinho de Hipona. Primeiro, Paulo em Atenas discursou no "lugar" do Deus desconhecido sob a sabedoria humana. Não comoveu ao tratar da ressurreição. Segundo, tempos depois, na cidade portuária de Corinto, alterou o discurso e fez sucesso tratando da loucura da cruz. Conferir Atos dos Apóstolos, 17, 15-33 e Primeira Epístola aos Coríntios, I, 17, 2-16.

3 Conferir “O papado e seus perigos", BURCKHARDT, J. A Cultura do renascimento na Itália: um ensaio. Tradução Sérgio Tellaroli. São Paulo: Cia. das Letras, 1991. p. 90-107. Ver também, FIRPO, Massimo. "O Cardeal". In: GARIN, E. (Org.). O homem renascentista. Tradução Maria Jorge Vilar de Figueiredo. Lisboa: Presença, 1991. p. 59-97. 
mera formalização ritual da vida social e coletiva e outra individual, bastante próxima de características próprias do Renascimento.

Se o cristianismo caracterizou-se, tradicionalmente, por uma postura de remordimento de consciência relativamente aos dilemas éticos, atrelada ao conceito de pecado, a predisposição de sua existência esteve relacionada apenas à necessidade de reconhecimento - por parte do crente - da distinção entre bem e mal, tomada como modelo da idéia de pecado original. Este princípio geral entrou em crise no processo de secularização e do ateísmo prático durante o Renascimento. Se um homem transformava a si próprio em grande, transformava-se, pela mesma razão, em bom. Se o bem e o mal não dependiam mais da relação de cada um com Deus, ser abandonado por Ele também deixava de ser significativo como fora na Idade Média, num processo de exclusão recíproca. Esta parece ser uma das bases do ateísmo prático do Renascimento. Ao mesmo tempo, e juntamente com o desenvolvimento da individualidade burguesa, a idéia de religião como relação pessoal com a Divindade tornava-se, redundantemente, individualizada e cada vez mais subjetiva. Este é o fundamento de um certo "cristianismo racional" ou "religião tolerante da razão", projetada durante o Renascimento, que pode ser denominada, anacronicamente, de atitude deísta, entretanto, sem o significado que o Iluminismo conferiu ao deísmo. Atentos ao movimento de secularização, lido pelo viés dos desmandos morais e de abertura de uma crise sem precedentes dos valores religiosos pela alta hierarquia da Igreja, Erasmo, Lutero, Morus e Collet projetaram o humanismo cristão ou filosofia de Cristo ${ }^{4}$ como retomada dos valores autênticos do Evangelho, projeto abortado por Lutero ao disparar de modo irreversível o movimento reformista. ${ }^{5}$ Em verdade, esteve em curso durante o século um movimento precursor do humanismo cristão intitulado devotio moderna, de

4 "Nocampodafé, ainteriorizaçãoe individualização da experiência religiosa eramtambémexigências peculiares aos humanistas, que lutavam por uma religião renovada. O chamado humanismo cristão, ou filosofia de Cristo, desenvolveu-se principalmente no Norte da Europa, centralizado na figura de Erasmo de Rotterdam e de seus companheiros mais próximos, como Thomas Morus e John Colet. A obra de Erasmo, O Elogio da Loucura, constitui o texto mais expressivo desse movimento. Todo repassado de fina ironia, ele ataca a imoralidade e a ganância que se haviam apossado do clero e da Igreja. O formalismo vazio a que estavam reduzidos os cultos, a exploração das imagens e das relíquias, o palavrório obscuro dos teólogos, a ignorância dos padres e a venda das indulgências. Segundo essa corrente, o Cristianismo deveria centrar-se na leitura do Evangelho (Erasmo publicou em 1516 uma edição do Novo Testamento, apurada pela crítica filológica), no exemplo da vida de Cristo, no amor desprendido, na simplicidade da fé e na reflexão interior. Era já o anseio da reforma da religião, do culto e da sensibilidade religiosa que se anunciava e que seria desfechada de forma radical, fraccionando a cristandade, por outros humanistas, como Lutero, Calvino e Melanchton." SEVCENKO, N. O renascimento. 13. ed. Campinas: Unicamp/Atual, 1988. p. 20.

5 A propósito, conferir “Aforismo 61”, In: NIETZSCHE, F. W.O AntiCristo. 4. ed.Lisboa: Guimarães \& C, 1975. 
inspiração agostiniana e com origem nos Países Baixos, que buscava mais a piedade que a especulação filosófica, como retorno aos autênticos princípios evangélicos.

Da história da filosofia - neoplatonismo à parte - apenas duas escolas apresentaram uma igualdade de aceitação perante filósofos e leigos durante o Renascimento: estoicismoe epicurismo. ${ }^{6} \mathrm{O}$ estoicismo tem sido considerado a filosofia da vontade e do heroísmo, cujo fim supremo - único bem do homem - não é o prazer, mas a felicidade gerada pela virtude, pois o bem moral é exatamente o que incrementa o logos, a natureza racional. Assim, a felicidade estóica é apatia e impassibilidade - o retirar-se da polis em crise. O epicurismo, por sua vez, tem sido a filosofia que propõe o refúgio numa vida prudente, dedicada à prática de prazeres moderados. Segundo a doutrina epicurista, o critério único da moralidade é o sentimento, pois somente as sensações "colhem o ser" de modo infalível. O prazer é confrontado à dor, como por analogia o bem em contraponto ao mal. $\mathrm{O}$ epicurismo tem duas finalidades: ataraxia e aponia: repouso do espírito e repouso do corpo. O que ambas escolas têm em comum é o predomínio do controle do comportamento e a orientação moral num mundo em crise - do mundo helênico em crise.

A moral estóica, desde a Antigüidade, foi tida como incoerente, ${ }^{7}$ também não foi tranqüila a aceitação do epicurismo, mesmo ao final da Idade

6 Ver "Ricerche sull'epicureismo del Quattrocento", In: GARIN, Eugenio. La cultura filosofia del rinascimento italiano: Ricerche e documenti. Milano: Bompiani, 1994. p. 72-92.

7 "Viu-se nela (moral estóica) um conflito latente entre uma inspiração naturalista, que nos prescreve viver em conformidade com a natureza, e uma inspiração precursoramente 'formalista', que tenderia a definir a vida do sábio por sua harmonia interna, ela própria adquirida ao preço de uma 'indiferença' geral às circunstâncias exteriores. De fato, não há contradição entre essas duas aproximações e se quer com efeito lembrar-se que a própria natureza é concebida pelos estóicos como um todo solitário e harmonioso, de maneira que, passando da harmonia representada da natureza à harmonia efetivamente realizada em si mesmo, o sábio nada mais faz, para retomar uma expressão de V. Goldschmidt, que realizar a mesma 'estrutura' em diferentes níveis. Não deixa de ser verdade que os estóicos hesitaram sobre o como dessa passagem. Oideal teria sido deduzir a regra prática de uma interpretação da ordem do mundo. Mas a ordem do mundo não se deixa sempre facilmente reconhecer no detalhe; o estoicismo exige então de nós um ato de fé na racionalidade oculta do universo, completado por uma técnica do uso das representações: trata-se, com efeito, de considerar como indiferente o que é em si explicável, logo racional, mas que não sabemos ainda explicar: a doença, o sofrimento, a morte etc. Essa técnica provisória corria o risco de se enrijecer num indiferentismo generalizado, parente próximo do ceticismo. Éo que sucedeu, desde a Segunda geração do estoicismo, com a dissidência de Ariston de Quios (primeira metade do século II a.C.), que ensinava que a dialética e a física, já que a virtude é o único bem, nada mais são que curiosidades vãs." AUBENQUE, Pierre. "As filosofias helenísticas: estoicismo, epicurismo, ceticismo.” In: CHÂTELET, F. (Org.). A filosofia pagã : do século VI a.C. ao século III d.C. Coleção História da Filosofia, Idéias, Doutrinas. Tradução Maria José de Almeida. Rio de Janeiro: Zahar, 1973, p. 178-179.

Rev. Filos., v. 19, n. 24, p. 61-75, jan./jun. 2007 
Média, como lembra Burckhardt ao refletir acerca da negação de Epicuro por Dante. Burckhardt escreveu:

A repulsa de Dante por Epicuro, ou por aquilo que considerava ser a doutrina deste, era certamente sincera. O poeta da vida eterna tinha necessariamente de odiar aquele que negava a imortalidade. $\mathrm{O}$ mundo não criado nem governado por Deus, tanto quanto o objetivo mesquinho da existência que parecia ser o suporte daquele sistema filosófico, não poderia ser mais avesso à natureza de Dante. Contemplando-se, porém, mais de perto a questão, verificar-se-á que certos princípios filosóficos da Antigüidade causaram-lhe uma impressão em face da qual sua crença no ensinamento bíblico da condução divina do mundo recuou. Ou teria sido movido por suas próprias especulações, pela influência da opinião predominante ou pelo horror à injustiça que então governava o mundo que ele abandonou inteiramente a crença numa Providência especial? ['Inferno', VII, v. 67-96]. Afinal, seu Deus deixa todos os detalhes da condução do mundo nas mãos de um ser demoníaco - a Fortuna - que nada mais faz senão alterar, emaranhar as coisas terrenas e ao qual, em sua indiferente bem-aventurança, é dado ignorar o lamento dos homens. E ainda assim, no entanto, Dante se apega inexoravelmente à idéia da responsabilidade moral dos homens: acredita no livre-arbítrio. (BURCKHARDT, 1991, p. 359).

Não existiu uma discrepância entre a visão de mundo e a prática estóico-epicurista, ao tempo do Renascimento e tal verdade foi formulada teórica e praticamente. Como exemplo, o cortesão, inventado por Castiglione, dada a vivência na corte de Urbino, é o aparentado mais próximo desta concepção de vida. As duas escolas surgiram na época da "decadência" da polis grega, popularizaram-se e difundiram-se na Roma dos Césares. Foram forçadas a enfrentar a perda da moral e da coesão da comunidade, mas também procuraram uma resposta individual à pergunta: como devemos viver? Epicurismo $\mathrm{e}$ estoicismo compõem a arte de viver, mais que uma moral de salvação pessoal. Para ambas, as leis do universo são dadas para todos os seres humanos. O homem nasceu num mundo sem finalidade dado por natureza, que não oferece a ninguém um objetivo individual ou qualquer sentido global de vida. A tarefa do homem - diferentemente de um objetivo transcendental à vida humana consiste em realizar um equilíbrio sóbrio da existência. Portanto, a meta destas filosofias é a conquista da liberdade interior - sobretudo para o estoicismo. Para o estóico, o ato de disciplinar a natureza humana, pelo ascetismo, torna-se obrigatório. O epicurista, por seu turno, vivendo longe do mundo, pode 
objetivamente afirmar sua autonomia dando livre curso às afeições. Na ausência de um ambiente corrupto, as afeições só podiam ser dirigidas para os prazeres nobres, sãos e moderados, tais como: amizade, cultivo da ciência, serenidade, boa música, boa conversa.

Em escala considerável, os renascentistas assimilaram os princípios epicuristas relativos ao prazer. E leram que, segundo Epicuro,

O prazer é o primeiro bem e nos é natural, por essa mesma razão não escolhemos todos os prazeres, mas muitas vezes os deixamos de lado quando podem ser o motivo de maior angústia [...] Todo prazer, por estar em relação conosco, é bom; entretanto, nem todo prazer deve ser escolhido; toda dor é um mal, mas nem todas devem ser evitadas [...]. Quando afirmamos que o prazer é a meta, não nos referimos aos prazeres sensuais do libertino, como pensam aqueles que nos ignoram, que defendem outra escola de pensamento ou que nos entendem erroneamente. O que temos em vista é o ser livre da dor no corpo e da angústia na mente. A isso damos o nome de vida agradável, e não obtida pelo beber e festejar contínuos, pela satisfação dos nossos apetites com rapazes e mulheres, ou pelos banquetes dos ricos, mas pelo raciocínio sóbrio, pela procura paciente dos motivos para escolha e recusa e pela nossa libertação das falsas opiniões que mais contribuem para prejudicar a nossa paz de espírito. (GUAL, 1996).

E o discípulo Diógenes de Enoanda sintetizou a doutrina de Epicuro em quatro princípios: enquanto vivemos, não há morte; os deuses não intervêm nos assuntos do mundo, nem se interessam pela vida dos homens - os mortais são cada vez mais responsáveis pelas suas ações, o que corrobora com a moral do ateísmo prático; a felicidade é possível, é um dever moral e a dor é superável, por meio de técnicas ensinadas pelo próprio Epicuro. De modo complementar para o olhar renascentista, os estóicos, talvez não por acaso, foram os primeiros a imaginar - para além do mito - ilhas paradisíacas ditas, anacronicamente, utópicas.

Durante o Renascimento, de certa forma estoicismo e epicurismo fundiram-se, transformaram-se numa atitude básica frente à realidade ou numa forma de conduta de matiz moral, que pôde acompanhar sistemas filosóficos bastante diferentes. Entretanto, mantiveram seus fundamentos na realidade a que os homens são obrigados a enfrentar, independentemente dos desejos, sonhos e processos de individuações. Tal fusão é o ponto de partida das ações, que disparariam repercussões no mundo, e que 
só os homens, com conduta moral adequada, com ações necessárias, podem devem - dar significado ao mundo.

As figuras históricas de Sócrates e de Jesus formaram o paradigma de conduta moral durante o Renascimento. Ambos representavam ideais morais tão abstratos - ao menos para o homem do Renascimento - que, em função deste caráter de abstração, foi possível encontrar similitudes entre um e outro. Foram considerados avatares morais pelas suas proeminências humanas, historicamente dadas. O papel de Jesus e a sua missão como messias, tão importantes para o mito cristão, foi relegado para segundo plano. No entanto, os aspectos humanos de sua vida, ensinamentos e sofrimentos - o homem Jesus - foram aos poucos e aos trancos secularizados. Os resultados de uma forma mitológica findaram por gerar outra. O que é comum às duas figuras de Sócrates e de Jesus é o viver autêntico e intencional da própria vida, a aceitação de todas as consequiências morais e de tudo o que o destino trouxe, incluindo a morte de mártir, a idéia do ensinamento e o caráter rústico do cotidiano de suas vidas. Vidas vividas em frugalidade, como, supostamente, também os romanos viviam, ao tempo da Roma republicana, como quer Maquiavel nos Discorsi.

Universalidade, apelo democrático, aceitação ativa do destino, possibilidade de uma interpretação estóica da vida, conteúdo moral abstrato isento de qualquer objetivo concreto além da virtude, são as propriedades que tornaram possível a transformação dos aspectos comuns ou semelhantes de Sócrates e de Jesus em símbolos genéricos e últimos do ideal renascentista de homem. A propósito, Heller (1982) escreveu que:

A fusão destas duas figuras universais, democráticas e mentoras dos homens, ou a sua hegemonia, lado a lado, como heróis míticos reinantes, constituía a forma mais abstrata e simultaneamente mais tangível de realização da síntese das tradições clássica e cristã. Constituía uma medida do progresso da secularização, do aparecimento de um certo grau de autonomia humana e da revivescência moderna dos ideais estóico epicurista. Na medida em que estas figuras gigantescas se tornaram 'nossas', os homens reconheceram-se a si próprios como suas criações.

No século passado, talvez atualizando aquela fusão estóicoepicurista, Nietzsche escreveu que o redentor anticristão e antiniilista teria o corpo de César e a alma de Cristo. ${ }^{8}$

8 Alusão à passagem: “[...]- A posição de exceção e poder desses seres, comparada com a dos nobres de até então: o César romano com a alma do Cristo". NIETZSCHE, F. Kritische studienausgabe. Fragmento 27 [60]. Verão-Outono de 1884, v. 11, p. 289. Indicação do Prof. Jorge Luiz. 
O esforço de separar o mito cristão e o mito greco-romano da história factual foi uma das primeiras manifestações dos humanistas do Renascimento. No mesmo passo, não se negava a verdade da tradição cristã, mas não reconhecia sua verdade como "histórica". A verdade do mito cristão já não era $a$ medida, em termos da realidade objetiva, dado que não era concebida como uma expressão dela. A verdade do mito era fábula, complexo estético, verdade medida pelo conteúdo moral, não pelo conteúdo propriamente histórico. Outra manifestação foi a propensão à análise dos conteúdos de verdade histórica do mito, além da tendência de transformação das figuras mitológicas em personalidades históricas e, ainda, dos conflitos mitológicos em conflitos históricos. No decurso do Renascimento, observou-se um corpo unitário de mitos, uma vez que as histórias e as personagens dos próprios mitos grecoromanos e judaico-cristãos fundiram-se - em alguns casos foram substituídas - por obra de poetas, pintores e escultores. Figuras de Cristo e Maria foram substituídas pelos heróis César, Brutus, os Gracos, a indicar um dos caminhos descendentes do processo de individualização moderna.

Todos esses aspectos, característicos da consciência do poder criativo e autocriativo do homem renascentista, compõem-se com uma das mais significativas experiências da humanidade. Conviviam no pensamento do homem renascentista a idéia de perfectibilidade infinita e o pressuposto de que o processo infinito de aperfeiçoamento só poderia realizar-se pelo esforço dos próprios homens, independentes da causa divina. No entanto, haveria nexos entre mitologia, alegoria, ateísmo prático e história durante o Renascimento?

À compreensão de tais nexos, Cassirer apontara para a significação das formas simbólicas concretas ${ }^{9}$ sob o universo filosófico do Renascimento, particularmente às re-apropriações dos temas míticos de Adão e de Prometeu. E grande parte desta re-apropriação encontra-se disseminada cronologicamente em obras como Genealogie deorum gentilium libri, de Giovanni Boccaccio; De laboribus Herculis, de Coluccio Salutati; Mythologiae sive explicationum fabolarum libri decem, ${ }^{10}$ de Natale Conti $;{ }^{11}$

9 Conferir PORTA, M. A. G. “Cassirer e a Filosofia das Formas Simbólicas”. Éthica. Rio de Janeiro: Universidade Gama Filho, v. 8, n. 1. p. 128-152, 2001.

10 Do qual Bacon retirara - em parte - inspiração para escritura da obra De sapientia veterum, sobretudo as passagens acerca da releitura humanista utilitarista do mito de Prometeu, porém sem mencionar a fonte, conforme demonstração de Charles Lemmi. Ver "A nova ciência e o símbolo de Prometeu", In: ROSSI, Paulo. Os filósofos e as máquinas - 1400-1700. Tradução Federico Carotti. São Paulo: Cia. das Letras, 1989, p. 141-149.

11 CONTI, Natale. Mythologiae sive explicationum fabularum libri decem. Veneza: Aldo Manucci, 1551. Referência extraída de ROSSI, Paolo. p. 146-175, n. 28.

Rev. Filos., v. 19, n. 24, p. 61-75, jan./jun. 2007 
Spacio de la bestia trionfante, de Giordano Bruno; De Sapientia Veterum, de Francis Bacon e, extra limite do Renascimento, em Scienza Nuova, de Giambattista Vico. Interpretar os mitos não tem sido novidade. Os poemas épicos de Homero e os inspirados de Hesíodo, uma vez transcritos para a língua grega, dispararam críticas e desconfianças pelos excessos representados nas façanhas dos deuses e nas gestas dos heróis.

Contudo, a primeira crítica mais sumarenta das reapropriações renascentistas dos mitos encontra-se em Vico, que admirava a originalidade dela, porém discordava da abordagem, assim como não aprovava integralmente o tratamento dado por Platão aos mitos. Vico escreveu:

Em virtude da descoberta dos princípios da poesia, dirimiu-se a opinião da sabedoria inatingível dos antigos, que tanto se desejava descobrir, de Platão a Bacon de Verulamio, De sapientia veterum, a qual foi sabedoria vulgar de legisladores que fundaram o gênero humano, não mais sabedoria oculta de sumos e raros filósofos. Assim, como se começou a fazer com Júpiter, hão de se considerar inoportunos todos os sentidos místicos de altíssima filosofia, dados pelos doutos às gregas fábulas e aos hieróglifos egípcios, como hão de resultar naturais os sentidos (significados) históricos que uns e outros, naturalmente, deviam conter. (VICO, 1999).

Como quer Vico (1999) "[...] as mitologias devem ter sido os falares próprios das fábulas (que é o que o termo significa), pois, sendo as fábulas [...]' gêneros fantásticos, as mitologias devem ter sido suas próprias alegorias." Monotemático, o pequeno livro A sabedoria dos antigos (De Sapientia Veterum), de Francis Bacon, opera de forma alegórica a interpretação de algumas fábulas retiradas da mitologia grega. Depois de recontá-las com brevidade e economia de detalhes - na maioria dos trinta e um capítulos - o Autor interpreta-as. Como em outros textos de Bacon, sobremaneira em Novum Organum, a "interpretação", contrariamente a "antecipação" dos antigos e medievais, é a palavra-chave para compreensão da operação proposta. Tal procedimento traz à luz aspectos práticos - técnicos, morais, políticos - das fábulas, subsumidos em conteúdos de suposta aparência enigmática. O resultado mais imediato finda por levar águas para o moinho das concepções baconianas de ciência e de técnica - como pares complementares.

É consensual que Bacon - sob o teto do humanismo utilitarista adotara a divisão das ciências desde um plano mais geral, que é a partilha em História ou ciência da memória; Poesia tomada como ciência da imaginação e, por último, Filosofia como ciência da razão. Se durante largo período a obra 
em pauta encontrava-se inscrita como pertencente à produção literária do Autor, desde os estudos de Lemmi e Rossi passou a compor o espectro filosófico dele. Em vida, Bacon recebeu o devido reconhecimento pelos Ensaios e pela A sabedoria dos antigos, escrita em latim, evitara de saída os barbarismos que a língua inglesa permite. Afinal, Bacon pinta melhor miniaturas que grandes painéis - como os aforismos do Novum Organum.

Por que Bacon lança mão da alegoria? O texto parece apontar para o que é sabido: a alegoria diz $A$ para significar $B$, com possibilidade de ser tomada como metáfora continuada de validade universal. A abordagem baconiana resgata o que a alegoria sublima. Neste ponto, é impossível não recordar Benjamin e as especulações contextualizadoras acerca da alegoria como "resolução do profano no sagrado" (BENJAMIN, 1984).

A concepção alegórica tem sua origem no contraste entre uma physis culpada, instituída pelo Cristianismo, e uma natura deorum mais pura, que se encarnava no Pantheon. Na medida em que a Renascença renova o elemento pagão, e a Contra-Reforma o elemento cristão, a alegoria precisa também renovar-se, como a forma de sua confrontação. ${ }^{12}$

Mesmo fora de contexto histórico-cultural específico, pode-se afirmar que o procedimento baconiano, sumariamente, encontra-se plausível de entendimento desde que seja estendida a perspectiva crítica benjaminiana.

As interpretações alegóricas das fábulas - em De Sapientia Veterum - são desiguais em densidade e em profundidade. Em grande parte, relata rapidamente o mito e desliza para interpretações por demais objetivas. Em outros casos, há detalhamento de enredo, sobrecarga de análise e interpretação complexa. Nesta linhagem, os destaques são para "Pã, ou Natureza"; "Cupido, ou átomo"; "Dédalo, ou o mecânico"; "Esfinge, ou Ciência"; "Prosérpina, ou Espírito" e; "Prometeu, ou condição humana", extenso e denso. Para as interpretações acerca do campo da natureza, há referências

12 BENJAMIN, p. 249. Como a literatura não é apenas ficção, mas sondagem do tempo, do que ocorre no presente e do que promete o futuro, difícil não recordar o poema "Alegoria", de Baudelaire: "Com seu olhar convoca inteira a humana raça. / É que esta virgem sabe: o seu ventre é infecundo, / No entanto necessário à marcha deste mundo, / E que a sua beleza é sempre um dom sublime / E que extrai o perdão de todo infame crime. I Ah, que ela ignora o Inferno e olvida o Purgatório, / E quando vier - Ó Noite - o seu fim ilusório, / Há de encarar a Morte e sem nenhum gemido / Sem ódio e sem amor - como um recém-nascido." In: BAUDELAIRE, Charles. As flores do mal. 2. ed. Tradução de Jamil Almansur Haddad. São. Paulo: Difusão Européia do Livro, 1964. p. 275.

Rev. Filos., v. 19, n. 24, p. 61-75, jan./jun. 2007 
pontuais a Demócrito e, em menor número, a Lucrécio. No mesmo passo, paira a sombra da invenção de Maquiavel - alla verità effetuale della cosa - na incidência de problemas políticos e morais.

A título de demonstração, o capítulo "Pã, ou Natureza" apresenta interpretação rica e detalhada, a par de conter muito do que o Autor pensa acerca da natureza ou de sua revisão conceitual. A fábula analisada reaparece ampliada no Livro II, do De Augmentis Scientiarum, o que indica, que para além de exercício interpretativo, o Autor buscava sustentação para a nova concepção de conhecimento da natureza. A abordagem sugere, outrossim, aproximações - em determinadas passagens - com as misturas infernais registradas na tragédia Thyestes. $\mathrm{O}$ mundo - representado figurativamente por cornos - fornece elementos de proximidade com o ideário que sustenta que o homem, mesmo vivendo entre feras, contém em si a possibilidade de elevação espiritual. Eis passagem sugestiva:

A circunstância de representar-se o mundo com cornos, e de esses cornos serem grossos na base e estreitos na ponta, tem relação com a imagem de uma natureza que se alteia em forma de pirâmide. Porquanto os indivíduos são infinitos e arregimentam-se em espécies [...] Destarte a natureza, contraindo-se à medida que sobe, parece finalmente encontrar-se num ponto. Não espanta, pois, que os cornos de Pã arranhem o céu: os picos, ou formas universais da natureza, de certa maneira ascendem para Deus. E arremata num átimo: "Vede como a passagem da metafísica para a teologia natural é pronta e breve!". (BACON, 2002).

Ao final do livro, quase como desabafo, Bacon registrou: "Na verdade, acho a sabedoria dos antigos semelhante a uvas malpisadas: alguma coisa é espremida, mas as melhores partes se perdem.."13

A metáfora baconiana vale também para o tempo atual em relação à sabedoria do Renascimento. Menos como desabafo, mais como constatação.

\section{Referências}

AUBENQUE, Pierre. "As filosofias helenísticas: estoicismo, epicurismo, ceticismo.” In: CHÂTELET, F. (Org.). A filosofia pagã: do século VI a.C. ao século III d.C. Coleção História da Filosofia, Idéias, Doutrinas. Tradução Maria José de Almeida. Rio de Janeiro: Zahar, 1973. p. 178-179. 
BACON, F. A sabedoria dos antigos (De Sapientia Veterum). Tradução de Gilson César Cardoso de Souza. São Paulo: UNESP, 2002.

BAUDELAIRE, Charles. As flores do mal. 2. ed. Tradução de Jamil Almansur Haddad. São Paulo: Difusão Européia do Livro, 1964.

BENJAMIN, Walter. Origem do drama barroco alemão. Tradução de Sergio Paulo Rouanet. São Paulo: Brasiliense, 1984.

BORGES, Jorge Luis. Atlas. Buenos Aires: Sudamerica, 1984.

BACON, F. A sabedoria dos antigos (De Sapientia Veterum). Tradução de Gilson César Cardoso de Souza. São Paulo: UNESP, 2002. p. 96.

BURCKHARDT, J. O papado e seus perigos. In: A cultura do renascimento na itália: um ensaio. Tradução de Sérgio Tellaroli. São Paulo: Cia. das Letras, 1991.

CHÂTELET, F. (Org.). A filosofia pagã: do século VI a.C. ao século III d.C. Coleção História da Filosofia, Idéias, Doutrinas. Tradução de Maria José de Almeida. Rio de Janeiro: Zahar, 1973.

CONTI, Natale. Mythologiae sive explicationum fabularum libri decem. Veneza: Aldo Manucci, 1551. Referência extraída de ROSSI, Paolo. n. 28, p. 146-175.

GARIN, E. (Org.). O homem renascentista. Tradução de Maria Jorge Vilar de Figueiredo. Lisboa: Presença, 1991.

GARIN, E. Ricerche sull'epicureismo del Quattrocento. In: La cultura filosofia del renascimento italiano: Ricerche e documenti. Milano: Bompiani, 1994.

GUAL, Carlos Garcia. Del placer como bien supremo. In: EPICURO. Epicuro. Madrid: Alianza, 1996.

HELLER, Agnes. O homem do renascimento. Tradução de Conceição Jardim e Eduardo Nogueira. Lisboa: Presença, 1982.

HUIZINGA, Johan. O declínio da idade média. Tradução de Augusto Abelaira. Braga: Ulisseia, 1996.

NIETZSCHE, F. Kritische studienausgabe. Fragmento 27 [60]. Verão-Outono de $1884.11 \mathrm{v}$. 
NIETZSCHE, F. W. O antiCristo. 4. ed. Lisboa: Guimarães \& C, 1975.

PORTA, M. A. G. Cassirer e a Filosofia das Formas Simbólicas. Éthica, Rio de Janeiro, v. 8, n. 1, p. 128-152, 2001.

ROSSI, Paolo. A nova ciência e o símbolo de Prometeu. In: Os filósofos

e as máquinas - 1400-1700. Tradução de Federico Carotti. São Paulo: Cia. das Letras, 1989.

SEVCENKO, N. O Renascimento. 13. ed. Campinas: Unicamp/Atual, 1988.

VERNANT, J. P. Do Mito à Razão. A formação do pensamento positivo na Grécia arcaica. In: Mito e pensamento entre os gregos: estudos de psicologia histórica. Tradução de Haiganuch Sarian. São Paulo: Difel/Edusp, 1973.

VICO, G. A ciência nova. Tradução de Marco Lucchesi. Rio de Janeiro: Record, 1999.

Recebido em/Received in: 20/05/2007 Aprovado em/Approved in: 02/06/2007 